\title{
Correspondence
}

\section{Stray light in the Tübingen perimeter}

TO THE EDITOR, British Journal of Ophthalmology

SIR, I was interested in the paper by Weale and Wheeler (1977). As it happens I have been under suspicion of possibly suffering from incipient glaucoma and in the course of its investigation have had repeated field examinations, mainly on the Tübingen perimeter. I became aware, in viewing the target, of glare emanating from the lamp below, which is intended to illuminate background of the bowl. This definitely affected the visibility of the target, more especially of course in the lower field. I found that placing my hand below my chin eliminated this effect and I believe an obturator has been designed to eliminate the defect in the particular

\section{Measuring pupil size}

TO THE EDITOR, British Journal of Ophthalmology

SIR, It is well known that variation in pupil size will affect visual acuity. This phenomenon has been a problem for those conducting epidemiological surveys of visual acuity, especially when the testing has been conducted in areas of direct sunlight. The problem is further compounded by the difficulty of measuring pupil size in people with heavily pigmented irides, in particular in dark-skinned races.

I have found a simple technique to overcome these difficulties. With commercially available macrophotography equipment it is relatively easy to photograph the eyes of a test subject at the time of testing. With the equipment set to the same magnification a photograph of a rule calibrated in millimetres is also taken. By first

\section{Notes}

\section{European Ophthalmic Pathology Society}

The European Ophthalmic Pathology Society held its 16th Annual Meeting in Munich, Germany, on 14-17 June. The meeting was scientifically and socially of an exceptionally high standard and was excellently organised by Professor O.-E. Lund and Mrs Lund. It began with a reception by the Bavarian Government in the Residenz (residential palace). The Bavarian Ministerpräsident was represented by the Bavarian State Minister for Education and Culture, Professor Dr Hans Maier, and Mrs Maier. The reception was combined with a visit to the Schatzkammer (treasure chamber). The scientific meeting was

\section{Glaucoma Course}

The Glaucoma Service of the Wills Eye Hospital will hold its annual glaucoma course on 14-15 April 1978. The cost will be $\$ 175$ ( $\$ 50.00$ for residents with accompanying letter from department chief), which includes course and instrument on which I was tested. The problem did not arise in the Goldmann perimeter, whose design is different.

Perhaps it would be desirable for all ophthalmologists to try out their equipment themselves and, therefore, possibly discover unexpected difficulties.

Yours faithfully,

Greenock Eye Infirmary,

W. O. G. TAYLOR

Greenock PA15 1TS

\section{Reference}

Weale, R. A., and Wheeler, C. (1977). A note on stray light in the Tübingen perimeter. British Journal of Ophthalmology, 61, 133-134.

projecting the slide of the rule to determine the magnification on to the particular screen one can accurately measure the pupil size in projected slides.

Using this technique in the brightest summer conditions in Central Australia I have found that the pupil diameter of Europeans with blue irides ranges from $2 \cdot 0$ to $2.5 \mathrm{~mm}$ and that for full-blood Australian Aborigines the range is 2.0 to $2.6 \mathrm{~mm}$.

$$
\text { Yours faithfully, }
$$

HUGH R. TAYLOR

National Trachoma and Eye Health Programme, Royal Australasian College of Ophthalmologists, 27 Commonwealth Street, Sydney, NSW, Australia held in the Hotel Bayerischer Hof, and the official dinner took place at the Palais Montgelas of this hotel. The social programme furthermore comprised attendance at the opera Tosca at the National Theatre, and the last day of the meeting ended with a visit to the Schleissheim and Lustheim castles and a boat tour on the Lake Starnberg bringing the company to the restaurant Berg for an informal Bavarian dinner. Dr W. R. Green (Baltimore) was the honoured guest. The next meeting of the society will be held in Belgrade, Yugoslavia, with Professor Olga Litricin as organising secretary. meals. Further information from Kenneth Benjamin, MD, 1419 Spruce Street, Philadelphia, Pennsylvania 19102, USA. 